\title{
O QUE HÁ ENTRE CRISTIANISMO, ÉTICA E MUNDO MODERNO?
}

\author{
WHAT IS THERE AMONG CHRISTIANITY, ETHICS AND THE MODERN AGE?
}

Luís Gabriel Provinciatto*

\section{RESUMO:}

Tomando como ponto de partida a obra Eu sou a verdade: por uma filosofia do cristianismo, de autoria do filósofo francês Michel Henry (1922-2002), este trabalho se ocupa em compreender como é possível estabelecer uma relação entre três temas centrais aí presentes, a saber: cristianismo, ética e mundo moderno. Não se trata, obviamente, de uma ligação evidente entre temas, sendo um a consequência de outro. A proposta de Henry é, partindo do campo fenomenológico, buscar as intuições fundantes do cristianismo, fazendo um retorno às fontes do Novo Testamento. A intenção deste trabalho, então, é apresentar uma leitura crítica do texto, mostrando ao leitor algumas nuances presentes nas entrelinhas da obra, tais como: a perspectiva fenomenológica empregada por Henry, a possibilidade de uma crítica recíproca entre cristianismo e mundo moderno e a importância da práxis nesse resgate da fonte cristã, donde a fundação de uma ética.

PALAVRAS-CHAVE: Cristianismo. Mundo moderno. Práxis. Ética. Michel Henry.

\section{ABSTRACT}

Taking as a starting point the work I am the truth: for a philosophy of Christianity, authored by the French philosopher Michel Henry (1922-2002), this paper is concerned with understanding how it is possible to establish a relationship among three central themes present there, namely: Christianity, ethics and the modern age. It is not, of course, an obvious connection between themes, one being the consequence of another. Henry's proposal, starting from the phenomenological field, seeks the founding intuitions of Christianity, making a return to the sources of the New Testament. The intention of this paper is to present a critical reading of the text, showing the reader some nuances present in the lines of the work, such as: the phenomenological perspective employed by Henry, the possibility of a reciprocal criticism between Christianity and the modern age and the importance of práxis in this rescue of the Christian source, from which the foundation of an ethics.

KEY WORDS: Christianity. Modern age. Ethics. Praxis. Michel Henry.

\footnotetext{
* Doutorando em Ciência da Religião pela Universidade Federal de Juiz de Fora (UFJF) com bolsa CAPES. Mestre em Ciências da Religião (2016) e graduado em Filosofia (2014) pela Pontifícia Universidade Católica de Campinas (PUC-Campinas). E-mail: lgprovinciatto@hotmail.com. Este trabalho é resultado de duas comunicações apresentadas no $28^{\circ}$ Congresso Internacional da SOTER e no II CONACIR sob os respectivos títulos a seguir, cujos textos completos constam publicados nos anais de tais eventos: Por um cristianismo ético: a leitura filosófica de Michel Henry da práxis cristã e Cristianismo e mundo moderno na perspectiva fenomenológica de Michel Henry.
} 


\section{INTRODUÇÃO}

A fenomenologia está na esteira de muitos pensadores do século XX e em muitas escolas diferentes, tais como a alemã e a francesa. Há ainda, nessas mesmas escolas, uma centena de outras divisões, o que não empobrece a fenomenologia, mas, ao contrário, torna-a mais vigorosa, uma vez que a atividade filosófica, entendida como sendo a própria fenomenologia, faz-se possível. O que disso ainda chama a atenção é a possibilidade fundamental de fazer fenomenologia com diferentes aspectos. E mais: estabelecer pontes com outras temáticas mantendo a fenomenologia como principal solo de fundamentação.

Nesse cenário encontra-se a proposta fenomenológica de Michel Henry (1922-2002), da qual aqui se destaca uma de suas últimas obras publicadas em vida, Eu sou a verdade: por uma filosofia do cristianismo. Originalmente, a obra foi publicada em 1996, na França, e caracteriza-se, sobretudo, pela operação fenomenológica realizada com o cristianismo. Devese ainda levar em consideração outras duas publicações desse mesmo período e que possuem uma estreita afinidade temática com a obra acima mencionada: Encarnação: por uma filosofia da carne e Palavras de Cristo, original e respectivamente publicadas em 2000 e 2002. Atentase também para o fato de que a proposta fenomenológica de Henry está no contexto de uma "cristologia filosófica", compreendendo esta como uma possibilidade contemporânea de reaproximar a prática filosófica da teológica: o ponto de partida de uma cristologia filosófica é eminentemente cristológico, isto é, referente ao ser de Cristo com ênfase em sua relação com Deus e em sua historicidade.

Esses elementos tornam a obra de Michel Henry um arcabouço filosófico a ser investigado, o que vem acontecendo aos poucos e em diferentes áreas de pesquisas acadêmicas em solo brasileiro. Nesse sentido, o presente trabalho busca compreender a relação entre cristianismo, ética e mundo moderno estabelecida nas entrelinhas da obra Eu sou a verdade, tomando-a como principal recorte teórico e lançando a seguinte problemática: o que há, de fato, nessa relação? Estariam tais temas associados numa relação de causa e efeito,

\footnotetext{
${ }^{1}$ Deve-se atentar para o seguinte: o termo "cristologia filosófica", melhor trabalhado pelo pensador Xavier Tilliete (1990), está inserido num contexto de giro teológico pelo qual passou a fenomenologia desenvolvida, sobretudo, por pensadores franceses no século XX, tais quais Jean-Luc Marion, Jean François Courtine e Michel Henry. Não se trata de utilizar o termo "giro" para designar "uma de tantas modas intelectuais, tão frequentes e passageiras na filosofia” (RESTREPO, 2010, p. 117), mas para designar um modo próprio de desenvolver o pensamento, resgatando o cruzamento entre as fontes judaica e cristã, fundamentos da cultura ocidental. Além disso, uma das principais intenções desse giro teológico não é fazer apologia da fé, mas mostrar a relevância do desenvolvimento de uma fenomenologia encarnada, ou seja, "sua compreensão exige a abertura a uma relação até agora impraticada com o fenômeno, caracterizado agora não por seu conteúdo de presença, mas justamente por seu excesso de doação" (RESPRETO, 2010, p. 116).
} 
sendo um a consequência do outro? De saída, este trabalho almeja contribuir na resolução desse questionamento por ora levantado, mas sem a pretensão de esgotá-lo e, para isso, assume outro recorte objetivo assim justificado: a obra Eu sou a verdade, dividida originalmente em 13 capítulos, receberá outra divisão, por blocos temáticos, ou seja, os capítulos serão reorganizados por afinidade temática dentro da própria obra.

Identificam-se quatro blocos temáticos: dos capítulos um a cinco a preocupação do autor é mostrar a diferença entre a verdade do cristianismo e a verdade do mundo ${ }^{2}$; do sexto ao nono, problematiza-se a vivência do homem; do décimo ao décimo segundo capítulo a centralidade é a práxis cristã; o último capítulo e a conclusão giram em torno da relação entre o cristianismo e o mundo moderno. Diante disso, a operação aqui realizada é analítica, pois acredita-se que, partindo desse recorte objetivo e dessa metodologia, alcançar-se-á a devida compreensão de como é possível aproximar o cristianismo, a ética e o mundo moderno sob a perspectiva fenomenológica que perpassa toda essa obra de Henry.

\section{A COMPREENSÃO DO QUE SEJA CRISTIANISMO}

Interessante perceber desde o início a presença de um elemento comum entre esses blocos temáticos e que, na verdade, está em Eu sou a verdade, bem como em Encarnação e Palavras de Cristo: a preocupação eminente pela relação entre fenomenologia e cristianismo, o que faz com que o pensamento de Henry se aproxime do pensamento teológico. Isso, porém, conduz ao seguinte alerta: "ao longo do seu pensamento, percebe-se que a teologia não é o seu ponto de partida, mas um ponto de chegada." (MAGALHÃES, 2012, p. 229).

O apontamento de Magalhães leva adiante essa perspectiva de definição, fazendo com que se exponha qual a compreensão de "cristianismo" trazida por Michel Henry. Antecipa-se

\footnotetext{
${ }^{2}$ Essa primeira dicotomia precisa ser mais bem compreendida para que não haja dubiedade na interpretação da obra. Na verdade, a diferença entre a "verdade do mundo" e a "verdade do cristianismo" é essencial: enquanto a primeira se revela como sendo um "fora de si", a segunda se mostra enquanto revelação, ou seja, é o manifestar da própria manifestação. A "verdade do mundo" fala de coisas criadas, não sendo capaz de criá-las propriamente, ao passo que a "verdade do cristianismo" fala da vida, pois "o primeiro traço decisivo da Verdade do cristianismo é que ela não difere em nada do que ela torna verdadeiro" (HENRY, 2015, p. 41). Aqui há, então, uma aproximação muito evidente entre verdade do cristianismo e verdade da vida. Diante disso, o exemplo do sofrimento se torna mais compreensível: a verdade do mundo fala sobre o sofrimento, mas não sofre; a verdade da vida é "a palavra do sofrimento" (HENRY, 2014b, p. 105) e, conforme anota o próprio Henry: "encontramos aqui uma relação essencial própria do cristianismo, que lhe confere sua extrema originalidade: a relação entre a Verdade e a Vida. [...] A Vida é Verdade porque ela se revela a si mesma e porque essa revelação de si - essa autorrevelação - constitui o fundamento de toda verdade concebível" (HENRY, 2014b, p. 105-106).
} 
também que a compreensão de "cristianismo" apontada pelo filósofo mostra qual o principal elemento da análise fenomenológica por ele pretendida. Lê-se, então, o seguinte:

\begin{abstract}
A que chamaremos, portanto, cristianismo? $\mathrm{O}$ que se encontra expresso num conjunto de textos designados pelo título de Novo Testamento é o que se entende por cristianismo - e parece que com boas razões. Sim, porque onde se poderia buscar o "conteúdo" do cristianismo a fim de refletir sobre o que ele considera como a verdade, senão no corpus constituído pelos Evangelhos, Atos dos Apóstolos, pelas epístolas destes, de Paulo, de Tiago, de Pedro, de João, de Judas e, enfim, pelo Apocalipse, atribuído ao mesmo João? Não é a partir desse corpus que foi elaborado este conjunto dos dogmas que definem o cristianismo? O conhecimento do cristianismo - e assim toda reflexão sobre sua possível "verdade" - não passa pelo conhecimento desses textos? Somente sua análise minuciosa pode conduzir, ao que parece, à inteligência do que é verdadeiramente o cristianismo em seu núcleo essencial. (HENRY, 2015, p. 7-8, grifos nossos).
\end{abstract}

A preocupação ao definir qual o entendimento dado ao cristianismo aponta necessariamente para o conteúdo da operação fenomenológica: o texto do Novo Testamento. Isso faz com que o texto não seja considerado somente em seus aspectos linguísticos. $\mathrm{Na}$ verdade, o aspecto linguístico possui na fenomenologia henryana uma importância de segunda ordem, pois o que lhe interessa, de fato, é o texto em sua fenomenalidade, ou seja, o texto carregado de vitalidade, de significação. O que isso significa? Significa que "a verdade do cristianismo, não tem precisamente nenhuma relação com a verdade que ressalta da análise dos textos ou de seu estudo histórico" (HENRY, 2015, p. 10). A essencialidade do texto é entendida como um fenômeno. E mais: tal fenômeno, ou melhor, o essencial ao texto é percebido fenomenologicamente. Isso faz com que seja feito um regresso à essência do cristianismo, àquilo que torna o próprio conteúdo do texto significativo: trata-se de buscar a essência do cristianismo.

Soma-se a essa busca a importância da compreensão e interpretação daquilo que o texto anuncia: isso que é anunciado possui vitalidade, ou seja, está carregado de significação. $\mathrm{O}$ texto e seu interlocutor, dessa maneira, estão carregados de espiritualidade, compreendendo-a nesses termos:

Espiritualidade está profundamente ligada com o que nós somos. Faz parte do nosso ser. Espiritualidade tem a ver com qualidade de vida, que envolve comunhão com Deus e com o nosso próximo. Como é parte do que nós somos, ela envolve também o nosso corpo. Assim, espiritualidade não é somente algo que se refira à alma ou a coisas que não podemos ver ou tocar. Espiritualidade envolve o ser humano como um todo, em todos os momentos da vida. (PIRES, 2005, p. 15). 
Assim sendo, o texto do Novo Testamento dá significado ao que seja o cristianismo na medida em que é compreendido e interpretado em sua espiritualidade, pois esta está arraigada à vida encarnada do interlocutor do texto. Destacando ainda: "a encarnação não é, em primeiro lugar, da ordem do projeto, mas da existência imediata porque não há uma ideia a priori do corpo que deve se encarnar." (RIBEIRO JÚNIOR, 2015, p. 550) e, por isso, a palavra cristã anunciada pelo texto do Novo Testamento é já compreendida e sempre a compreender. Essa dinâmica dá origem a um círculo compreensivo, a uma hermenêutica virtuosa, conforme aponta o seguinte comentário:

Tem-se aqui, não um círculo vicioso, mas um círculo virtuoso, onde a hermenêutica parte do pressuposto que não se compreende tudo, entretanto, nunca se fica sem compreender algo, pois a compreensão somente é possível se já existe algo compreendido. (CARNEIRO, 2013, p. 84).

Isso é de tal importância e está presente desde o início da obra porque é justamente nos textos que se encontra o conteúdo central do cristianismo: a "verdade" de Cristo. Os textos do Novo Testamento, então, proporcionam a operação fenomenológica pretendida por Henry e lhe dão as bases para as problemáticas, bem como para as resoluções levantadas ao longo da obra. É a partir de tais problemáticas, percebidas nos blocos temáticos há pouco anunciados, que se pretende perceber e compreender a relação entre o cristianismo - agora devidamente apresentado -, a ética e o mundo moderno, problematizado a seguir.

\section{CRISTIANISMO E MUNDO MODERNO: A POSSIBILIDADE DE UMA CRÍTICA RECÍPROCA}

Este segundo momento se inicia com um recorte epistemológico, agora no interior da obra Eu sou a verdade: opera-se aqui com a compreensão de modernidade presente, sobretudo no primeiro e no quarto bloco temático, com especial atenção aos capítulos três - "Esta verdade que se chama vida" - e treze - "O cristianismo e o mundo". Justifica-se tal escolha por ser justamente nesses trechos em que se dá, respectivamente, a compreensão do que sejam a modernidade e a colocação do cristianismo compreendido por essa mesma modernidade.

A compreensão de modernidade, por sua vez, abrange, a princípio, o modo estritamente racional de compreender a realidade, isto é, busca-se a abstração conceitual a partir da análise da experiência imediata e das qualidades sensíveis. Nesse sentido, a matemática é o melhor modo de expressar com exatidão o conhecimento científico. Por isso, 
figuras como René Descartes (1596-1650) e Galileu Galilei (1564-1642) são fortemente mencionadas por Henry como exemplos do pensamento moderno. Esta, então, é a característica central trazida por Henry do período moderno: o conhecimento não pautado na subjetividade corpórea, mas tão somente na objetividade matemática, ou seja, “conhecer de modo adequado o universo implica então que, tendo sido afastadas por ilusórias essas propriedades sensíveis, nós captemos as figuras dos corpos reais - estudo que pende da geometria, ciência racional e rigorosa" (HENRY, 2015, p. 57).

Diante disso, a modernidade trabalha com uma redução inicial, a saber: a exclusão das qualidades sensíveis, chegando ao ápice com a eliminação da corporeidade do indivíduo. Por sua vez, o cristianismo opera com o indivíduo, destacando a sensibilidade, a essência invisível, como agente mobilizador da ação. Isso conduz à seguinte afirmação: "a ciência crê que continua a mover-se no domínio que é o seu quando reduz essas propriedades a seu embasamento físico material. O que lhe escapa é que qualidades sensíveis não existem nunca como simples propriedades de um objeto.” (HENRY, 2015, p. 58). Percebe-se, a partir disso, não uma negação da ciência, mas uma nova possibilidade de significá-la a partir da vida, daí a necessidade de compreender, primeiramente, o que há entre cristianismo e mundo moderno.

Essa possibilidade de ressignificar a ciência a partir da vida coloca, de antemão, uma questão: qual a compreensão de "vida" trazida por Michel Henry? Não se trata, certamente, da vida aos moldes da ciência moderna, que, para colher resultados, elimina toda subjetividade possível da vida humana. Nas palavras do próprio Henry:

\footnotetext{
Quanto a mim emprego este termo para designar a vida fenomenológica, isto é, "o que se vivencia a si mesmo", pelo simples motivo de que a nossa vida é tão-só isso e nada mais. Ela não é somente e apenas um sentir, o sentir de tudo o que sentimos, mas antes um "sentir-se a si mesmo", nessa imediação absoluta e patética [...] e que faz com que tudo o que assim se experiencia seja habitado pela certeza de ser, seja vivo. Então viver quer dizer provar-se. (HENRY, 2010, p. 6).
}

Interessante destacar um ponto a partir desse excerto: a essência da vida se configura como uma espécie de saber, daí o emprego dos termos "imediação absoluta e patética", ou seja, a vida, nessa perspectiva fenomenológica trazida pelo autor, está provando-se (experienciando-se) corporalmente a todo momento, qualificando-se como um pathos, um saber, que, por sua vez, diferencia-se do saber científico ordinário; nesse saber da vida, "nesse outro conhecimento tudo é dado de uma só vez” (HENRY, 2010, p. 7): não é necessária uma complexa elaboração científica para sugerir ao sujeito o sentimento da dor, a dor acontece na vida de maneira absoluta, sem qualquer mediação. 
Com isso, chega-se a uma primeira crítica à modernidade: a vida não precisa estar elaborada em dados objetivos e visíveis para provar-se a si mesma; ela a faz a todo momento. Lê-se, então: "a fenomenalidade própria da vida, isto é, esse nosso padecimento nela, que nos constitui, explica que ela não seja visível, sem dúvida porque, na realidade, é por natureza invisível" (HENRY, 2010, p. 7). O retorno à fonte textual cristã permite perceber o resgate da dimensão invisível como fundamental à existência. Antes, porém, mostra-se como plausível a compreensão de uma crítica recíproca entre cristianismo e mundo moderno.

\subsection{A crítica cristã à modernidade}

Conforme destacado, a ciência moderna deixa de lado a sensibilidade. Abandonar a sensibilidade implica, necessariamente, num abandono da própria vida, uma vez que a própria sensibilidade é um modo de expressar a vitalidade da vida. Nesse sentido, a fecundidade prática da cientificidade moderna acaba por sacrificar a vida humana e isso acontece, por exemplo, na denominada ciência da vida, a biologia. As palavras de Henry dirigidas à ciência biológica:

\footnotetext{
É no campo desta [a biologia] que ela [a ciência moderna] manifesta seu efeito mais impressionante, orientando a investigação para os embasamentos químicos e, em seguida, físicos dos fenômenos biológicos e de seu funcionamento específico. Que ao termo de tal investigação só se encontrem processos físico-químicos e nada que se assemelhe à experiência interior que cada vivente faz de sua vida, ao próprio fato do "viver", isto é, a esta autorrevelação original que qualifica a Vida como uma essência fenomenológica pura e a Verdade no sentido do cristianismo, aí está uma consequência absolutamente necessária. (HENRY, 2015, p. 58-59).
}

A ciência moderna, então, reduz a própria vida a aparatos objetivos quantificadores, possíveis de serem analisados pela física e pela química, modelos aplicados do próprio conhecimento matemático. Não há aí, porém, nenhuma surpresa, pois desde seus primeiros desenvolvimentos a ciência moderna lidou com a objetividade. Por isso, o que a biologia, enquanto ciência moderna, encontra em sua investigação são "valores" quantitativos e não qualitativos. Busca-se, na verdade, um valor universal válido independentemente das mudanças qualitativas, ou seja, o conhecimento da própria biologia não leva em consideração o vivente em si, tudo aquilo que nele é invisível, tal qual a própria vida, mas somente a sua potencial capacidade de transformar-se num algoritmo. A ciência moderna alcança resultados 
físico-químicos lidando somente com os aspectos objetivos e externos de um corpo, este também reduzido a uma mera quantidade.

A crítica se esboça, então, nestes termos: a ciência se esquece, de fato, da vida em sua invisibilidade, em sua sensibilidade e em sua corporeidade. Tudo o que há de qualitativo é desprezado pela ciência moderna. Nessa direção, aponta Furtado: "nenhum ser possível poderia nos fazer sentir o que quer que seja se o conteúdo afetivo desse sentimento tivesse que nos ser aportado do exterior, como efeito de uma causa ou mesmo como significação constituída." (FURTADO, 2008, p. 242). Isso tem uma implicação imediata: a vida prova a si mesma e não necessita que isso lhe seja dito a partir de algo externo a si mesma, tal qual pretende a própria ciência.

A crítica voltada à cientificidade moderna, então, diz respeito ao alijamento da própria vida, isto é, à redução de seu aspecto qualitativo para a assunção de um valor objetivo. $\mathrm{O}$ cristianismo, por sua vez, mostra, conforme indicam os textos do Novo Testamento, o aspecto vivencial da vida: "a Vida fenomenológica cuja essência é experimentar-se a si mesma em seu 'viver'.” (HENRY, 2015, p. 64). Aí são encontradas as mais humildes sensações da vida, tais como os sofrimentos e as alegrias, os desejos e os temores: o cristianismo ressalta a condição fundamental da vida, isto é, vivê-la em seu experimentar a si mesma a cada momento; o cristianismo postula o invisível como fundamento do próprio viver, pois nele a vida sente a si mesma. Por isso, a modernidade é um momento decisivo: ela dissipa essa importância apontada pelo cristianismo, esse zelo pelo invisível da vida, e coloca no lugar a objetividade da ciência, pautada pelo conhecimento matemático, por aquilo que é visto.

$\mathrm{Na}$ verdade, isso tudo "é o que se produziu desde a Antiguidade clássica e, sem dúvida, bem antes dela" (HENRY, 2015, p. 65). A modernidade, porém, é o momento no qual, com maior força, dissipou-se a importância da vida, pondo no lugar a objetividade científica, culminando no abandono de sua essência. Isso é o que tem em vista Henry quando afirma, respondendo à questão sobre como foi possível abandonar o fundamental à vida:

\footnotetext{
A resposta impõe-se em sua simplicidade: substituindo essa essência dissimulada da vida pela consideração dos vivos. Mas para que esta substituição cumprisse seu papel, para que ela alcançasse a ocultação pelo pensamento ocidental da essência original da vida [experimentar-se a si mesma] e de seu "viver", era preciso que ela fosse reproduzida no próprio plano dos viventes que acabavam de substituir a vida ante o olhar desse pensamento. Era preciso que, a propósito de cada vivente, seu aparecimento exterior na verdade do mundo substituísse sua autodoação no viver da vida, autorrevelação desta. (HENRY, 2015, p. 64-65, grifo nosso).
} 
E isso tem uma consequência imediata: o postulado do objetivo. E mais: a prioridade do visível em detrimento do invisível, ou seja, a substituição do incalculável, a vida em si mesma, pelo calculável, a vida em seus caracteres objetivos e quantitativos. Assim, então, resume-se a crítica cristã à modernidade: raptar a vida dela mesma.

\subsection{A crítica moderna ao cristianismo}

Interessante também perceber como Michel Henry coloca a crítica dirigida pela modernidade ao cristianismo e, nesse movimento, como o cristianismo pode se deparar com sua própria essência, resgatando-a. Disso surge uma nova possibilidade de dar significado à ciência, bem como de resgatar a dimensão invisível da vida. Antes, porém, é necessário deterse na crítica moderna ao cristianismo.

A crítica dirigida ao cristianismo: este desvia o homem da realidade, criando um "além imaginário" capaz de saciar todas as expectativas que não foram alcançadas na finitude da vida. Tal "além" é denominado como o "céu". Há aí um pressuposto que precisa ser evidenciado: a modernidade toma, e não poderia ser de outra maneira, a realidade objetiva como a única possível. Noutras palavras: é real aquilo que pode ser quantificado, medido e comprovado pela ciência. Por isso, desviar o homem dessa realidade é lançá-lo no campo imaginário, que não pode ser mensurado. E daí o principal desdobramento disso:

\footnotetext{
A invenção de outro mundo fantástico ou, melhor dizendo, fantasmático, esse lugar de satisfação imaginária de todos os desejos e de todas as aspirações que o homem não pôde realizar aqui embaixo - o "além" que este aqui embaixo reclama como o complemento indispensável de todas as faltas e de todas as frustrações. (HENRY, 2015, p. 329-330).
}

Tal crítica, no entanto, faz o mínimo sentido quando se percebe o seguinte: o próprio cristianismo esqueceu sua essência, fixando-se na elaboração de outra vida, uma vida no "céu”. Ou seja: o próprio desdobramento histórico do cristianismo, sua aproximação com o pensamento grego, sobretudo com o desenrolar de uma teologia metafísica, cindiu a vida de sua verdadeira realidade. Isso configura-se, na verdade, como uma verdadeira contradição, pois o cristianismo se desviou de seu projeto fundamental, aquele presente nos textos do Novo Testamento. Faz-se notar que Henry, ao apontar a crítica moderna ao cristianismo, pretende propor uma superação fenomenológica, resgatando o elemento essencial ao próprio 
fenômeno cristão. Nesse sentido, ter-se centrado numa realidade do "céu" que se desenhou, esta sim, como imaginária é uma contradição presente no próprio percurso cristão:

\begin{abstract}
A mais significativa [contradição] consiste na tentativa de edificar uma realidade nova, um novo Reino, desconhecendo as condições da realidade. Tal tentativa não pode senão desembocar no desaparecimento de toda efetividade, num puro "vazio" e esse lugar vazio, estranho à realidade, é o Céu do cristianismo (HENRY, 2015, p. $331)$.
\end{abstract}

Há de se perceber o seguinte: a crítica moderna permite o resgate das intuições fundadoras do cristianismo presentes, sobretudo, nos textos evangélicos. E mais: não se trata de um conhecimento teórico, mas prático. A superação fenomenológica proposta por Henry, então, resgata a dimensão essencialmente prática do cristianismo; resgata a dimensão trocada pelo "céu vazio". Trata-se de fazer notar a realidade a partir da Verdade da Vida. Nesse sentido, "a preocupação da fenomenologia se dá com a unidade, com as manifestações, com o tornar claras as fontes, o retorno ao originário, entrar no domínio da consciência, no domínio dos fenômenos" (PRASERES, 2014, p. 243), donde a afirmação: a operação fenomenológica realizada por Michel Henry na obra Eu sou a verdade permite perceber não uma contradição entre cristianismo e mundo moderno, mas uma possibilidade de superação de um e de outro pelo próprio movimento de retorno à dimensão originária, possibilitada pela análise minuciosa desenvolvida ora pelo cristianismo sobre a modernidade, ora por esta sobre aquele.

Isso faz com que se afirme: ambas as críticas permitem uma superação fenomenológica. O que isso significa? Por um lado, significa que o cristianismo pode ser reconduzido às suas intuições fundadoras, pondo novamente o acento decisivo no campo prático, isto é, na ação evangelizadora que encontra respaldo nos textos neotestamentários. E deve-se compreender muito bem a intenção dessa "ação evangelizadora": uma atitude tomada a partir do Evangelho, a partir da Verdade revelada pelo próprio Cristo enquanto Filho do Pai. Por outro lado, a própria ciência pode ter uma nova significação enquanto "palavra" humana compreendida a partir da dinâmica da vida. Essa noção de "palavra" também precisa ser esclarecida: não se trata de uma "palavra" por si existente - o que faria dela uma mentira -, mas a "palavra" como capacidade humana de expressão. "Palavra" enquanto linguagem.

Essa compreensão de "palavra" permite a anunciada superação da própria ciência moderna, pois esta agora pode ser compreendida pela ótica da vida. Destaca-se o comentário de Sansonetti: “[...] a verdadeira palavra de Deus é somente a que nos permite compreender o sentido divino das palavras humanas, uma espécie de Palavra antes da palavra, como é a 
Vida em sua natureza radicalmente fenomenológica." (SANSONETTI, 2006, p. 834). A preocupação da ciência há de se rearranjar, pondo, no entanto, a atenção sobre a vida em si, pois a compreensão da própria ciência é a partir da Palavra da Vida. A ciência há de ser, mesmo assim, palavra criada, pois se mostra na exterioridade do mundo e "falando do que se mostra na exterioridade do mundo, a palavra do mundo fala de um conteúdo que lhe é exterior e que, ademais, ela é incapaz de criar" (HENRY, 2014, p. 103). Nesse sentido, a palavra do mundo continua a falar sobre algo, o diferencial está no modo de se falar disso: a partir da vida. A vida, então, passa a ser o eixo central dessa possibilidade de superação da ciência moderna.

Essa possibilidade de superação ainda leva em consideração a possibilidade de valorar:

Só para a vida há valores. Não apenas só a vida pode agir, mas também só ela põe valores e só para ela os põe. Por conseguinte, ela é o único princípio de avaliação, isto é, de orientação da acção, quer se trate dos valores que correspondem às suas necessidades materiais quer aos valores de outra ordem. (HENRY, 2010, p. 12).

Isso significa que os valores são postos a partir da vida e a levam como ponto de referência. A ciência moderna, tal qual apresentada por Henry, destorce essa possibilidade, colocando a própria objetividade científica como referência, alijando-se da vida.

A possibilidade de superação também abarca o cristianismo, pois ao receber a crítica moderna de desvio de suas intuições fundamentais, encontra-se com seu momento de superação, resgatando a dimensão da realidade efetiva da vida, essa realidade que é invisível, mas não é vazia, tal qual o Céu desenhado anteriormente. Isso permite perceber que o que constitui a realidade é a própria vida. Diante disso, observa-se a preocupação de Henry com essa relação entre realidade e vida ao afirmar: "a realidade que constitui o conteúdo do mundo é a vida. Tal é a nova evidência: longe de fugir da realidade deste mundo, o cristianismo, que não conhece senão a vida, por isso mesmo não tem relação senão com esta mesma realidade". (HENRY, 2015, p. 343). Noutras palavras: o cristianismo não pode se cindir da realidade, pois o conteúdo desta é a vida. A vida, por sua vez, é o tema central fundante do próprio cristianismo, pois Cristo dirige-se aos homens na condição de vivente. Garante-se essa dimensão da palavra, pois "revelando-se a si mesma, a vida nos fala de si mesma" (HENRY, 2014, p. 101); e mais, fala nessa invisibilidade fundamental: 
É só assim que o sofrimento nos fala; ele nos fala em seu sofrimento. E o que ele nos diz, falando-nos desse modo, é que ele sofre, que ele é sofrimento. Descobre-se assim para nós, em sua extrema simplicidade, uma palavra a que as muitas teorias da linguagem nunca, a despeito de sua sofisticação, prestaram a menor atenção. Ora, essa palavra mais simples é também a mais singular. E sua singularidade consiste no fato de que essa palavra e o que ela nos diz constituem algo uno. (HENRY, 2014, p. 102, grifo nosso).

Diante disso, apresenta-se como fundamental compreender a relação entre cristianismo e a dimensão prática da existência, que, na verdade, não está apartada da dimensão teórica. A grande diferença, porém: o acento da vida não está na teoria, mas na prática, daí a possibilidade de uma ética pautada nesse próprio se manifestar da vida. A singularidade da palavra da Vida está nisso: conjugar a ação.

\section{A CENTRALIDADE DA PRÁXIS CRISTÃ}

A temática da práxis cristã coaduna-se com a problemática a respeito da relação entre cristianismo e mundo moderno e se encontra presente na obra Eu sou a verdade na parte que este trabalho denominou de terceiro bloco temático. Disso decorre a necessidade de apresentar, mesmo que brevemente, como o tema da ética torna-se central nessa discussão. Para isso lança-se mão da seguinte passagem:

Por mais extraordinárias e difíceis que pareçam ao homem as exigências da ética cristã, permanece o fato não menos extraordinário de que elas se enraízam em sua verdadeira natureza. Elas se propõem como salvaguarda dela. E é assim que fazem retornar a ela. (HENRY, 2015, p. 241, grifo nosso).

Anuncia-se, com efeito, que a ética cristã conduz o ser humano a um contato consigo mesmo. Essas "extraordinárias e difíceis exigências" baseiam-se, basicamente, no mandamento do amor, tema central dos Evangelhos. Caracteriza-se, com isso, que o mandamento do amor é capaz de salvaguardar a vida. A mensagem cristã faz notar a preponderância da vida justamente por recolocá-la no centro da discussão, algo que, aos olhos de Henry, a própria filosofia deixou escapar. Nesse sentido, pode-se afirmar que Michel Henry faz uma fenomenologia da vida em solo cristão, da qual aqui se destaca a seguinte característica:

Em primeiro lugar, ela assinala que o saber da consciência, que é objetivo e revela outra coisa, tem sua condição ontológica de possibilidade no saber da vida, isto é, na auto afecção ou pura experiência de si na imanência radical da afetividade. Nenhum 
ato revelaria algo se não se revelasse primeiro a si mesmo. A autoafecção da vida define seu viver enquanto se experiência a si mesma e implica uma automanifestação. Henry caracteriza a autoafecção como pathos por seu caráter afetivo e como carne porque se identifica com os poderes corporais na conjectura de seus exercícios. (WALTON, 2010, p. 135, tradução nossa).

A partir desse momento podem-se perceber as primeiras relações entre o cristianismo e a ética, pautando tal relação no "novo olhar" empreendido pelo autor francês a respeito da práxis cristã. O princípio da ação, então, é compreendido por Henry a partir da fenomenologia. O mesmo que dizer: “o princípio da ética cristã só se torna inteligível à luz de uma filosofia inteiramente nova da ação.” (HENRY, 2015, p. 245). Interessante fazer notar o que está nas entrelinhas dessa passagem, a saber: a relação latente entre ação e verdade, pois a ação é conduzida por uma verdade. O "novo olhar" lançado sobre a ação, sobre a práxis cristã, só é possível porque se percebe a radical mudança que o cristianismo opera no entendimento do que seja verdade.

No entendimento clássico, o termo ação consiste numa "passagem do interior ao exterior, do que não se vê ao que se vê". (HENRY, 2015, p. 246), ou seja, num processo objetivante. O cristianismo opera uma mudança radical nesse entendimento, colocando a verdade não como objetiva, isto é, externa ao sujeito, mas como componente própria de sua subjetividade. Conforme aponta Henry: “o cristianismo situa a ação no lugar que é o seu, ali onde fazer é fazer esforço, penar, sofrer, e isso até o momento de o sofrimento dessa pena transformar-se na alegria da satisfação". (HENRY, 2015, p. 246). A mudança radical, possível de ser vista por esta ótica fenomenológica, consiste na invisibilidade de toda ação, isto é, a ação, pertencente à vida, é, assim como a própria vida, secreta, invisível. Não se trata mais de uma verdade ou de uma ação guiada por elementos externos, por verdades objetivas, mas por uma ação guiada pelo mandamento próprio da vida: o amor. Concorda-se, de fato, com Carneiro quando este afirma: "a vida precede a ciência e não pode ou deve estar subjugada a ela." (CARNEIRO, 2013, p. 90). E agora se complementa esse aspecto: a linguagem da vida deve conduzir a linguagem do mundo, pois acima da lei externa está a invisibilidade da vida. Além disso, deve-se ter a capacidade de assegurar que não raras vezes a própria linguagem do mundo não consegue abarcar tudo aquilo que é provado pela vida. Nem sempre é possível traduzir a palavra da Vida.

O cristianismo opera nessa chave, pois com ele prepondera a vida e o amor. A práxis cristã está fundada na vida, no mandamento do amor. Toda prática revela-se, a princípio, não como objeto, mas antes como a si mesma para um sujeito. Isso condiz com a seguinte 
afirmação: "nesta revelação a si de minha ação, está inclusa a autorrevelação da vida e, assim, a de Deus. Cada uma de minhas ações é, portanto, revelada a Deus ao mesmo tempo em que se revela a mim e no próprio ato pelo qual o faz.” (HENRY, 2015, p. 249).

A operação fenomenológica realizada com a práxis cristã faz notar que um “cristianismo ético" retira a objetividade das ações, isto é, as ações são e dizem muito mais do que simplesmente um tornar-se objeto para, a partir disso, ser classificado e valorado. Isso destaca novamente a invisibilidade da vida e aí se percebe a relação entre verdade e ação não como sendo uma relação de correspondência, mas como uma relação recíproca, na qual as duas se implicam mutuamente. De acordo com Carneiro (2013, p. 91), "esta é uma experiência pela qual, no horizonte do mundo ocidental não foi realizada; a experiência da verdade não como correspondência entre a coisa e o dito sobre a coisa, mas da verdade como não-esquecimento, não-ocultamento (sic) ou desocultamento". Decorre disso a reafirmação de uma das intuições centrais à prática cristã: sua centralidade é o indivíduo enquanto sujeito em sua subjetividade. Ainda de acordo com Henry:

\begin{abstract}
O que se pede à ética são duas coisas, pelo menos: no plano individual, um núcleo de certezas que permitam que cada um conduza a sua vida; no plano coletivo, uma unidade que ofereça à humanidade, e em primeiro lugar a cada grupo social, a cada nação, a possibilidade de formar uma comunidade de comportamentos, que se construa um ethos neste solo de convicções e de pensamentos comuns (HENRY apud ROSA, 2006, p. 8).
\end{abstract}

A ética, então, encontra-se na própria vida do ser humano. Disso se poderia questionar: qual a relevância do cristianismo? Colocar a centralidade na própria vida, algo que o mundo moderno não realizou. E, conforme afirma Rosa (2006, p. 8), “do ponto de vista ético, a nossa época vive uma situação paradoxal: é detentora de um saber considerável, que cresce sem cessar, mas, ao mesmo tempo, dá mostras da mais completa ignorância quanto aos fins da ação e aos valores que os devem definir”. Na contramão dessa situação, a leitura desenvolvida por Henry faz ressurgir a ética cristã como possibilidade fundamental justamente por colocar em questão e problematizar a centralidade da vida em sua materialidade, em sua corporeidade, em sua subjetividade.

Além disso, pode-se perceber a contemporaneidade da mensagem cristã e como, a partir dela, é possível deslocar radicalmente o centro de toda ação, abandonando a ideia de uma "norma" objetiva para seguir um mandamento próprio à vida em si. Essa percepção é possível a partir do momento em que se recorda o seguinte: o texto do Novo Testamento é 
considerado enquanto fenômeno, ou seja, constitui Tradição, atualizando-se constantemente. Sem dúvida, isso está presente nas entrelinhas da relação entre cristianismo e ética, pois a leitura da práxis cristã leva essa possibilidade de atualização do texto como fundamento.

Há ainda de se concordar com Janilce Praseres (2014, p. 255) no seguinte: "o esboço ético que se forma a partir da Fenomenologia da Vida é que a ética não é exterior, ela é a teoria da ação essencial da vida, sendo assim o próprio agir sem mediação". Disso pode-se concluir: a operação fenomenológica feita por Michel Henry, no que tange à práxis cristã, mostra que o princípio da ação não é externo ao ser humano, mas intrínseco a ele mesmo. Noutras palavras: a "lei" não garante a possibilidade da ação, isso porque ela é elaborada mantendo o movimento interno-externo, a noção de verdade e ação como correspondência entre pensamento e prática, ou seja, tornando objetivo algo que é subjetivo. O cristianismo, ao contrário, aborda o princípio da ação a partir do sujeito, garantindo-lhe a possibilidade de agir. O mandamento do amor, nesse sentido, é puramente imanente. Reconhecer o mandamento do amor é reconhecer o chamado do próprio Deus à vida.

Essa motivação de crítica à lei dá-se porque o cristianismo entende a realidade a partir da vida, conforme destaca Henry: "esta motivação remete à tese central do cristianismo que coloca a realidade na vida. É precisamente porque a Lei é transcendente, exterior à vida e percebida por esta fora dela que ela se encontra privada da realidade". (HENRY, 2015, p. 252, grifo nosso). A lei não fornece nenhum tipo de capacidade ao sujeito para que ele possa agir de acordo com aquilo que é por ela descrito. A lei traz consigo um traço de contradição, pois indica algo e não dá possibilidades para a realização.

A possibilidade de agir é a característica desse terceiro momento temático que aqui se destacou. O que decorre disso: a possibilidade de aproximar o cristianismo e a ética por um viés fenomenológico, pois a fenomenologia, mesmo no entendimento de Henry, mantém sua máxima de "retorno às coisas mesmas", o que faz notar as intuições fundadoras do cristianismo e ver que nele há uma possibilidade real de agir a partir da vida. Soma-se a isso a afirmação de Sansonetti (2006, p. 823):

Isso não significa, porém, segundo uma abordagem filosófica mal entendida, submeter a verdade do cristianismo a uma medida substancialmente estranha, na qual a filosofia exerça o papel de parâmetro ao qual referir a veracidade das afirmações escriturísticas; trata-se, antes, de desenvolver uma compreensão imanente capaz de justificar a coerência e o significado de tais afirmações, as quais, de outro modo, poderiam parecer totalmente fantasiosas, senão até ridículas. 
É a partir disso que se pode notar, de fato, uma operação fenomenológica realizada em solo cristão. A filosofia, desse modo, não é um parâmetro para abordar o cristianismo, mas o próprio modo de lidar com o cristianismo. O cristianismo, então, não é um objeto de investigação ao qual se aplica um método, mas a própria realidade latente com a qual o autor se depara a todo momento. Com isso, novamente se justifica a escolha anunciada pelo próprio Henry de trabalhar com os textos do Novo Testamento: eles contêm as intuições fundadoras do cristianismo. E ainda destaca: "a verdade do cristianismo não tem precisamente nenhuma relação com a verdade que ressalta da análise dos textos ou de seu estudo histórico" (HENRY, 2015, p. 10), ou seja, ao operar fenomenologicamente com os textos é possível mostrar sua agudeza como nunca antes realizado.

\section{CONCLUSÃO}

A modo de fechamento do presente trabalho, pode-se dizer, a princípio: a relação que aqui se tentou evidenciar não está presente de maneira sequencial na obra Eu sou a verdade. Isso trouxe como consequência para o trabalho: a possibilidade de traçar uma linha no interior do pensamento de Henry expressado nessa obra, de modo a aproximar momentos temáticos e perceber como a operação fenomenológica por ele empregada está presente em todos eles, o que garante coerência à obra.

Além disso, o modo analítico empregado por este trabalho permitiu perceber que nas entrelinhas na discussão a respeito da relação entre cristianismo, ética e mundo moderno está presente uma questão de linguagem. E mais: de compreensão e interpretação de tal linguagem, ou seja, o círculo hermenêutico virtuoso não é adequado somente à análise textual do Novo Testamento, mas à própria dimensão prática da existência. Dessa maneira, a definição de espiritualidade apresentada no primeiro tópico deste trabalho perpassa a relação entre cristianismo - compreendendo sua fonte textual adequadamente -, mundo moderno salientando a possibilidade de superação da definição moderna do que seja ciência, tomando como eixo condutor a vida em sua essência invisível - e ética - sabendo que ela está arraigada à própria vida humana não como lei externa, mas como um agir sem mediação.

O cristianismo postula a ética centrada na vida, não compreendendo esta como valor objetivo, mas como possibilidade de ação sem mediação, daí a importância da espiritualidade. Isso também incide na possibilidade (fundamental) de superação da ciência moderna, pois, conforme aponta Henry: 
No campo aberto pela ciência moderna, não há nenhum homem. Longe de a transformação do conhecimento resultante da emergência do saber inteiramente novo da ciência moderna poder transformar ao mesmo tempo ou ao menos modificar nossa ideia de homem, o que constitui o ser-essencial deste, ela o suprime pura e simplesmente. Quanto ao saber obsoleto do cristianismo, um saber que data de dois milênios, não são dados inteiramente prescritos e inutilizáveis sobre o homem o que ele nos fornece: somente ele pode dizer-nos hoje, no meio da confusão mental generalizada, o que é o homem. (HENRY, 2015, p. 365, grifo do autor).

A ressignificação da ciência passa pelo seguinte: uma ciência a serviço da vida, donde a urgência do saber sobre o que é o homem. A definição moderna, na verdade, separa homem e vida, dando àquele uma definição definitiva, suprimindo a vida. O cristianismo, ao contrário, mostra a vida em sua incompletude, buscando sempre a definição virtuosa do que é o homem.

Essa busca virtuosa permite relacionar cristianismo, ética e mundo moderno, pois o primeiro traz em seus textos fundantes o caráter invisível e prático da existência, incidindo numa ética pautada pelo mandamento imanente do amor. Além disso, o cristianismo faz lembrar a dimensão prática da vida (práxis), algo esquecido pelas teorias modernas, que abarcam, inclusive, o próprio cristianismo. Por isso, cristianismo e mundo moderno estão relacionados, pois, o primeiro não pode se esquecer de suas intuições fundadoras, ao passo que a ciência deve se rearranjar, centrando-se na vida e postulando seus resultados a partir da vida e para a própria vida. $\mathrm{O}$ apontamento de uma crítica recíproca entre ambos mostra essa possibilidade de superação.

\section{REFERÊNCIAS}

CARNEIRO, Éverton Nery. Hermenêutica: um viés ético. Reflexus - Revista de teologia e ciências da religião, v. 7, n. 10, p. 79-96, jul.-dez., 2013.

FURTADO, José Luiz. A filosofia de Michel Henry: uma crítica fenomenológica da fenomenologia. Dissertatio, Pelotas, RS, v. 28, p. 231-249, 2008.

HENRY, Michel. As ciências e a ética. Covilhã: LusoSofia, 2010. Disponível em: < http://www.lusosofia.net/>. Acesso em: 22 fev. 2017.

HENRY, Michel. Eu sou a verdade: por uma filosofia do cristianismo. São Paulo: É Realizações, 2015.

HENRY, Michel. Palavras de Cristo. Tradução Carlos Nougué. São Paulo: É Realizações, 2014a. 
HENRY, Michel. Encarnação: uma filosofia da carne. Tradução Carlos Nougué. São Paulo: É Realizações, 2014b.

MAGALHÃES, Fernando Rosas. Caro cardo salutis. Uma cristologia a partir da carne (teologia a partir de Michel Henry). Humanística e teologia, Porto, v. 33, n. 2, p. 229-241, 2012.

PIRES, Frederico Pieper. O que é espiritualidade? Rio de Janeiro: MK, 2005.

PRASERES, Janilce Silva. A fenomenologia da vida: apontamentos sobre afetividade e nãointencionalidade para a fundamentação de uma ética no pensamento de Michel Henry. Griot - Revista de filosofia. v. 10, n. 2, p. 242-259, jul.-dez., 2014.

RESTREPO, Carlos Enrique. El "giro teológico" de la fenomenología: introducción al debate. Pensamiento y cultura - Revista de filosofía, v. 13, n. 2, p. 115-126, jul.-dez., 2010.

RIBEIRO JÚNIOR, Nilo. Elogio do inacabado: da fenomenologia à filosofia da alteridade. Sapere Aude, Belo Horizonte, v. 6, n. 12, p. 540-555, jul.-dez., 2015.

ROSA, José M. Silva. O "ethos" da ética na fenomenologia radical de Michel Henry. 2006. Disponível em: < http://www.lusosofia.net/>. Acesso em: 22 fevereiro 2017.

SANSONETTI, Giuliano. Cristo, verdade da Vida. ZUCAL, Silvano (Org.). Cristo na filosofia contemporânea: o século XX. São Paulo: Paulus, 2006.

TILlIETE, Xavier. Le Christ de la philosophie. Paris: Cerf, 1990.

WALTON, Roberto J. El giro teológico como retorno a los orígenes: la fenomenología de la excedencia. Pensamiento y cultura - Revista de filosofía, v. 13, n. 2, p. 127-140, jul.-dez., 2010. 